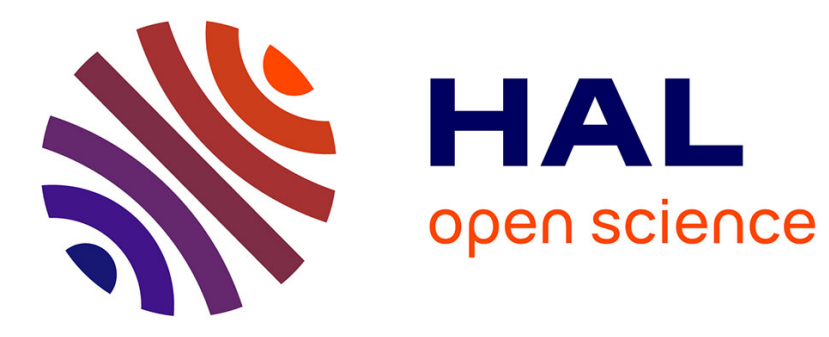

\title{
The Microwave Spectrum of Allyl Acetate
}

Ha Vinh Lam Nguyen, Halima Mouhib, Wolfgang Stahl, Isabelle Kleiner

\section{To cite this version:}

Ha Vinh Lam Nguyen, Halima Mouhib, Wolfgang Stahl, Isabelle Kleiner. The Microwave Spectrum of Allyl Acetate. Molecular Physics, 2010, 108 (06), pp.763-770. 10.1080/00268971003645354 . hal00588672

\section{HAL Id: hal-00588672 \\ https://hal.science/hal-00588672}

Submitted on 26 Apr 2011

HAL is a multi-disciplinary open access archive for the deposit and dissemination of scientific research documents, whether they are published or not. The documents may come from teaching and research institutions in France or abroad, or from public or private research centers.
L'archive ouverte pluridisciplinaire HAL, est destinée au dépôt et à la diffusion de documents scientifiques de niveau recherche, publiés ou non, émanant des établissements d'enseignement et de recherche français ou étrangers, des laboratoires publics ou privés. 


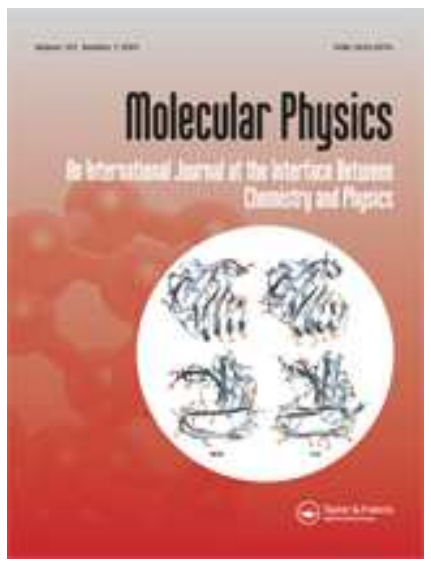

The Microwave Spectrum of Allyl Acetate

\begin{tabular}{|c|c|}
\hline Journal: & Molecular Physics \\
\hline Manuscript ID: & TMPH-2009-0353.R1 \\
\hline Manuscript Type: & $\begin{array}{l}\text { Special Issue Paper -HRMS Stabia 09/ High Resolution Molecular } \\
\text { Spectroscopy }\end{array}$ \\
\hline $\begin{array}{l}\text { Date Submitted by the } \\
\text { Author: }\end{array}$ & $11-J a n-2010$ \\
\hline Complete List of Authors: & $\begin{array}{l}\text { Nguyen, Ha Vinh Lam; RWTH Aachen University, Physical Chemistry } \\
\text { Mouhib, Halima; RWTH Aachen University, Physical Chemistry } \\
\text { Stahl, Wolfgang; RWTH Aachen University, Physical Chemistry } \\
\text { Kleiner, Isabelle; Université de Paris 12, LISA }\end{array}$ \\
\hline Keywords: & Microwave spectroscopy, Allyl acetate, Internal rotation \\
\hline
\end{tabular}

\section{S ScholarONE" \\ Manuscript Central}




\title{
The Microwave Spectrum of Allyl Acetate
}

\author{
H.V.L. Nguyen ${ }^{a}$, H. Mouhib ${ }^{a}$, W. Stahl ${ }^{a}$, and I. Kleiner ${ }^{b}$ \\ ${ }^{a}$ Institute of Physical Chemistry, RWTH Aachen University, Landoltweg 2, D-52074 Aachen, \\ Germany \\ ${ }^{\mathrm{b}}$ Laboratoire Interuniversitaire des Systèmes Atmosphériques (LISA), UMR 7583 \\ (CNRS/Univ. Paris 12 \& Paris 7), Université de Paris 12, 61 avenue du Général de Gaulle, F- \\ 94010 Créteil cedex, France
}

\author{
Corresponding author: Ha Vinh Lam Nguyen \\ Institute of Physical Chemistry \\ RWTH Aachen University \\ Landoltweg 2 \\ D-52074 Aachen \\ Germany \\ Phone: +492418094721 \\ Fax: +492418092365 \\ Email: nguyen@pc.rwth-aachen.de
}

\begin{abstract}
The Fourier transform microwave (FTMW) spectrum of allyl acetate

$\left(\mathrm{CH}_{3}-\mathrm{COO}-\mathrm{CH}_{2}-\mathrm{CH}=\mathrm{CH}_{2}\right)$ has been measured under molecular beam conditions. By comparing the experimental data with quantum chemical calculations we identified one conformer of $\mathrm{C}_{1}$ symmetry, in which the ethylene group is bent by an angle of approximately $129^{\circ}$ against the plane of the C-COO-C backbone. Large A-E splittings (in some cases up to 1 $\mathrm{GHz}$ ) of all lines due to internal rotation of the acetate methyl group were found. Analyzing the spectrum with the program BELGI-C $C_{1}$ yielded a torsional barrier of only $98.58(15) \mathrm{cm}^{-1}$.
\end{abstract}

Keywords: Microwave spectroscopy, Allyl acetate, Internal rotation 


\section{Introduction}

Molecular beam Fourier transform microwave (MB-FTMW) spectroscopy is an excellent tool to study the structure and dynamics of molecules in the gas phase. By this way a large number of molecules has been investigated, but surprisingly, only very few esters were among them, though they are a very important class of compounds in chemistry. This might be due to the fact that even small esters contain quite a large number of atoms which makes them too big for classical structure determination by isotopic substitution. Moreover, even under molecular beam conditions usually several conformers exist. Low barrier internal rotation of the acetate methyl group additionally increases the complexity of the spectra and makes assignment difficult. We tried to identify conformers of esters by comparing the experimental data with quantum chemical calculations and succeeded for some aliphatic esters such as ethyl acetate [1]. We were interested in allyl acetate because it is one of the smallest unsaturated ester. To our knowledge no microwave studies on allyl acetate have been carried out before.

Another motivation for this work was our interest in large amplitude motions. The acetate methyl group of allyl acetate shows internal rotation. From investigations on methyl acetate [2], where a barrier of the acetate methyl group of $99.559(83) \mathrm{cm}^{-1}$ was observed and from our own studies on ethyl acetate [1], where we found a barrier of $101.606(23) \mathrm{cm}^{-1}$, we expected also in this case a rather low hindering barrier on the order of $100 \mathrm{~cm}^{-1}$. On the other hand we could not exclude to observe a different value since an interaction with the ethylene double bond appeared possible.

Finally, our quantum chemical calculations on allyl acetate, carried out before beginning the experimental work, made us curious. A conformer with the ethylene group bent against the plane containing the ester group was predicted, whereas our intuition told us, that all heavy atoms should be located in a mirror plane. For the latter geometry the theoretical calculations predicted a local maximum in the potential. We expected that a microwave study would allow us to decide, which structure is the correct one. 


\section{Experimental}

All spectra were recorded using two MB-FTMW spectrometers in the frequency ranges 4 to $26.5 \mathrm{GHz}[3,4]$ and 26.5 to $40 \mathrm{GHz}$ [5], respectively. Allyl acetate was obtained from Merck Schuchardt OHG, Hohenbrunn, Germany, and used without further purification. A gas mixture containing $1 \%$ allyl acetate in helium at a total pressure of 100 to $200 \mathrm{hPa}$ was used throughout. We have chosen helium as a carrier gas because the cooling is not as effective as with argon or neon and therefore also higher J levels can still be observed.

The spectrometers can be operated in two different modes, the high resolution mode and the scan mode. In the high resolution mode all lines are split into doublets due to the Doppler effect. The molecular transition frequency is the center frequency, the splitting depends on both, the center frequency and the velocity of the molecular beam. The line width was approximately $8 \mathrm{kHz}$, the line positions can be determined with an accuracy of $1 \mathrm{kHz}$ for strong lines and $5 \mathrm{kHz}$ for weaker lines. A typical spectrum is shown in Fig. 1.

$<$ Fig. 1 approximately here $>>$

In the scan mode a series of overlapping spectra taken in the high resolution mode are automatically recorded and only the presence of lines is indicated in a broad band scan. An example is given in Fig. 2.

$<$ Fig. 2 approximately here $>>$ 


\section{Spectral Analysis}

We started our investigations by recording broadband scans in the frequency range from 9.3 to $10.0 \mathrm{GHz}$. Additionally, during the process of spectral assignment some smaller ranges on the order of 100 to $200 \mathrm{MHz}$ were scanned. In total 274 lines were found, many of them were quite strong. All lines were remeasured in the high resolution mode.

At the beginning of our studies on allyl acetate we assumed, the $\mathrm{C}_{\mathrm{s}}$ conformer with a symmetry plane (conformer I, shown in Fig. 3) should exist and it should be the most stable one. Taking this mirror plane as a constraint in quantum chemical calculations carried out with the program Gaussian 03 [6], we predicted the rotational constants and tried to use them for assigning the spectrum. The rotational constants are given along with the dipole moment components in Tab. 1. However, we found that the experimental and the theoretical spectra did not match at all.

Without this constraint using the MP2 method and the $6-311++\mathrm{G}^{* *}$ basis set a fully optimized structure was obtained, where the plane of the ethylene group was bent by an angle of $121.57^{\circ}$ against the ester group (conformer II, shown in Fig. 4). The rotational constants of this $\mathrm{C}_{1}$ conformer are also given in Tab. 1. We tried again to assign the spectrum with the new rotational constants and succeeded. However, the calculated and the experimental rotational constants differed by up to $2.5 \%$. The origin of this will be discussed later in this paper.

$<$ Fig. 3 and Fig. 4 approximately here $>>$

We started the assignment with the lines of the A species, which could be treated as an effective rigid rotor spectrum. On the basis of the rotational constants obtained by ab initio methods we predicted the spectrum with the program XIAM [7]. By trial and error the typical pattern of the $a$-type $4 \leftarrow 3$ R-branch could be identified. Fitting these lines with XIAM yielded already quite accurate $\mathrm{B}$ and $\mathrm{C}$ rotational constant, which were still improved by including other $a$-type R-branches. Finally, also $b$-type Q-branch transitions were identified, which enabled us to fit the A constant as well.

It should be noted that by our quantum chemical calculations the $c$ dipole moment component is predicted to be small but not zero. Therefore we were surprised that no $c$-type transitions could be found at all in the scans. After the spectrum had been assigned we were able to measure some $c$-type transitions using polarizing pulses with a power of 1 or $2 \mathrm{~W}$, whereas for $a$ - and $b$-type transitions a few $\mathrm{mW}$ turned out to be sufficient. The existence of $c$-type 
transitions proofs that no mirror plane is present within the conformer studied. It should also be noted that the $c$-type transitions were not split, which indicates that no tunneling of the ethylene group through the plane of the ester group occurs on the time scale of our experiment. A list of some $c$-type transitions is given as supplementary data (Tab. S3). Those $c$-type transitions were however very weak and we did not include them in our fits. In allyl acetate the rotational lines are split due to internal rotation of the acetate methyl group, which has a low barrier to internal rotation. Thus we expected very large A-E splittings from a few $\mathrm{MHz}$ up to $1 \mathrm{GHz}$ or more, depending on the respective transition. In the next step we predicted the E species transitions using XIAM. The barrier to internal rotation was assumed to be approximately $100 \mathrm{~cm}^{-1}$ as is was also reported for methyl acetate [2] and ethyl acetate [1]. The inertia of the methyl group was fixed to $3.2 \mathrm{u} \AA^{2}$, which we considered to be a reasonable value found in many molecules with methyl internal rotation. The angles between the internal rotor axis and the principal inertial axes of the molecule were calculated from the $a b$ initio geometry given in Tab. S4. The angles are given in Tab. 2.

We started the assignment of the E species lines with those which were close to the respective A species transitions. This holds for the $a$-type R-branch transitions, where the A-E splittings were only on order of 10 to $100 \mathrm{MHz}$. After fitting the internal rotation parameters and thereby improving our predictions, also $b$-type Q-branch transitions could be assigned, which were split by several $100 \mathrm{MHz}$ up to $1 \mathrm{GHz}$. In some cases scanning a small range of $5 \mathrm{MHz}$ was necessary to find the lines.

Using XIAM the barrier to internal rotation was determined to be $98.093(12) \mathrm{cm}^{-1}$. This can be compared to the barrier of the acetate methyl group of methyl acetate which is $99.559(83) \mathrm{cm}^{-1}$ and to the barrier of $101.606(23) \mathrm{cm}^{-1}$, which was found for ethyl acetate. All barriers are very close together, and obviously the double bond of allyl acetate does not affect the internal rotation.

Finally 109 A species and 62 E species lines were assigned and fitted again with the program BELGI-C $_{1}$ using the Rho Axis Method (RAM) [8]. This code allows us to calculate and fit transitions for asymmetric top molecules containing one $\mathrm{C}_{3 \mathrm{v}}$ internal rotor (like the $\mathrm{CH}_{3}$ group) and having a $\mathrm{C}_{1}$ point-group symmetry at equilibrium. The global BELGI- $\mathrm{C}_{1}$ code was used only twice up to now and compared to a perturbation treatment in the PAM axis system used in the JB95 code $[9,10]$. The results are shown in Tab. 2 and Tab. 3. A complete list of all fitted transitions is given as supplementary data (Tab. S1 and S2). 
As we have discussed in [1], XIAM is very user-friendly, and easier to use for assignment purposes, whereas Belgi- $\mathrm{C}_{1}$ is usually a better model to treat the internal rotation problem for low barrier molecules very accurately (see next section). 


\section{Results and Discussion}

The microwave spectrum of allyl acetate has been assigned with the programs XIAM and BELGI-C ${ }_{1}$. A comparison of XIAM and BELGI has been given in [1] and will not be repeated here again in detail. With XIAM a global fit of the A and E species was carried out (Fit II in Tab. 3). A standard deviation of $54.0 \mathrm{kHz}$ was obtained for 171 lines with $\mathrm{J}_{\max }=15$ and $\mathrm{K}_{\mathrm{a} \max }$ $=6$ (5) for the A (E) species respectively. In a second fit with XIAM (Fit III in Tab. 3) the internal rotation parameters were fixed to the values obtained from Fit II and only the A species lines were fitted. Here a standard deviation of $2.7 \mathrm{kHz}$ was found, which is close to

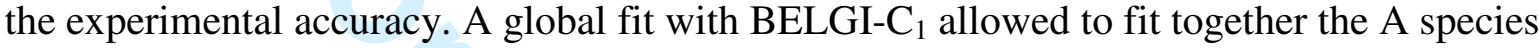
with a standard deviation of $2.7 \mathrm{kHz}$ and the E species with $1.2 \mathrm{kHz}$. The overall standard deviation is $2.3 \mathrm{kHz}$ which indicated that the model used in BELGI-C ${ }_{1}$ almost perfectly describes the observed spectrum. The reason for the better standard deviations obtained by the BELGI-C $\mathrm{C}_{1}$ code is that it uses a global approach dealing with the total set of torsional $v_{t}$ states (to a certain truncation level) associated with the internal rotation, and using one Hamiltonian and one set of parameters to fit the data. The model used in BELGI does therefore include all torsion-rotation interaction between different torsional states. On the other hand, in the local method used in XIAM, each torsional state is treated separately using its own Hamiltonian. In XIAM, certain off-diagonal matrix elements in $v_{t}$ are thus neglected (after removal by van Vleck transformations) which is a good assumption only in the high barrier limit. In the present case, the so called reduced barrier height $\mathrm{s}=4 \mathrm{~V}_{3} / 9 \mathrm{~F}$ is small (8.17) and thus the effect of those matrix elements are important and cannot be neglected. We note that in Tab. 2, we needed two terms which are symmetry allowed only for a $C_{1}$ internal rotor molecule. The $\mathrm{D}_{\mathrm{ac}}$ parameter (multiplying the $\mathrm{P}_{\mathrm{a}} \mathrm{P}_{\mathrm{c}}+\mathrm{P}_{\mathrm{c}} \mathrm{P}_{\mathrm{a}}$ operator) which essentially allows for the fact that the methyl top axis is not required by symmetry to lie in the principal inertial axis $a b$ plane is actually rather large. We also needed $\mathrm{d}_{\mathrm{ac}}$, which is its torsional dependence.

It should be noted that the internal rotation problem in BELGI-C $\mathrm{C}_{1}$ is treated in the rho axis system (RAM system) and consequently all parameters obtained also refer to this coordinate system. The original parameters from the BELGI- $\mathrm{C}_{1}$ fit are given in Tab. 2 . To compare these values with those obtained from XIAM, which refer to a principal inertial axis system (PAM system); all BELGI-C $_{1}$ parameters given in Tab. 2 were transformed from the rho axis system to the principal inertial axis system (Tab. 3).

To facilitate this transformation in a first step the tensor formed by the diagonal A, B, and C rotational constants and the off-diagonal elements $\mathrm{D}_{\mathrm{ab}}, \mathrm{D}_{\mathrm{bc}}$, and $\mathrm{D}_{\mathrm{ac}}$ is diagonalized yielding 
$\mathrm{A}, \mathrm{B}$, and $\mathrm{C}$ in the PAM system as well as the transformation matrix $\mathrm{v}$. The transformation matrix is used to calculate the elements of the rho vector $\rho_{a}=\rho \cdot v_{11}, \rho_{b}=\rho \cdot v_{12}$, and $\rho_{c}=\rho \cdot v_{13}$ in the PAM system. In a next step the moment of inertia of the methyl group $F_{0}$ and the direction cosines $\lambda_{\mathrm{ia}}, \lambda_{\mathrm{ib}}, \lambda_{\mathrm{ic}}$ between the internal rotor axis and the principal inertial axes $a, b$, and $c$ are calculated

$$
\begin{aligned}
& F_{0}=\sqrt{\frac{1}{\frac{\rho_{a}^{2}}{A^{2}}+\frac{\rho_{b}^{2}}{B^{2}}+\frac{\rho_{c}^{2}}{C^{2}}}}, \\
& \lambda_{\text {ia }}=\rho_{a} \cdot \frac{F_{0}}{A}, \quad \lambda_{i b}=\rho_{b} \cdot \frac{F_{0}}{B}, \quad \lambda_{i c}=\rho_{c} \cdot \frac{F_{0}}{C} .
\end{aligned}
$$

The barrier to internal rotation of the acetate methyl group is $98.55(13) \mathrm{cm}^{-1}$ using BELGI-C ${ }_{1}$ and 98.093(12) $\mathrm{cm}^{-1}$ using XIAM. The moments of inertia of the methyl group were fitted to yield 3.1861(17) $\mathrm{u}^{2}$ and 3.29046 (33) $\mathrm{u}^{2}$, using BELGI-C $\mathrm{C}_{1}$ and XIAM, respectively. Here the BELGI-C B $_{1}$ value appears somewhat smaller, whereas the XIAM value is slightly too high if compared with the methyl rotors in methyl acetate $\left(3.2085(26) \mathrm{u} \AA^{2}\right)$ [2] and ethyl acetate (3.16067(76) u $\AA^{2}$ ) [1]. However this discrepancy may also indicate that non-rigidity effects are important for $I_{\gamma}$ and these effects are treated very differently by the two methods. In the BELGI code, deviations of the $\mathrm{C}_{3 \mathrm{v}}$ symmetry for the methyl group is taken into account by higher-order interaction terms, whereas in XIAM only some higher $\left(4^{\text {th }}\right.$ order $)$ coupling terms between internal rotation and overall rotation are implemented.

For an unambiguous identification of the assigned conformer $a b$ initio calculations on MP2/6-311++G** level were carried out. From calculations on ethyl acetate and other esters we knew that this method gives reliable rotational constants, however it should be considered that the torsional force constant of the $\mathrm{C}-\mathrm{COO}$ bond is quite low and sometimes a rotation of both molecule fragments around this bond still improves the result. This rotation can be facilitated by freezing the dihedral angle $\varphi\left(\mathrm{O}_{3}-\mathrm{C}_{8}-\mathrm{C}_{11}-\mathrm{C}_{12}\right)$ at certain fixed values while all other parameters were optimized. In this case we calculated a full rotation of $360^{\circ}$ with a $10^{\circ}$ step width. The corresponding potential function is shown in Fig. 5.

$$
<\text { Fig. } 5 \text { approximately here }>>
$$

Obviously three stable conformers are generated by this rotation. Conformer II and III are a pair of enantiomers with the same rotational constants. A further conformer (conformer IV) is 
less stable and should have a symmetry plane. We also indicated a non-stable transition state ("conformer I") which is also of $\mathrm{C}_{\mathrm{S}}$ symmetry. All conformers described here are trans conformers. By rotation around the $\mathrm{O}_{3}-\mathrm{C}_{8}$ axis also three stable cis esters can be found, however these are much higher in energy and are unlikely to be observed under molecular beam conditions. Therefore we will not discuss them here. All geometry parameters are given in Tab. S4 to S7.

As can be recognized from Fig. 5 the dihedral angle $\varphi\left(\mathrm{O}_{3}-\mathrm{C}_{8}-\mathrm{C}_{11}-\mathrm{C}_{12}\right)$ for the energy minimum is $\pm 121.57^{\circ}$ for the conformers II/III. In Fig. 6 the rotational constants vs. $\varphi$ are drawn.

$<<$ Fig. 6 approximately here $>>$

The rotational constants $\mathrm{B}$ and $\mathrm{C}$ of conformer II have a relative deviation of $0.8 \%$, but for the A constant it is $2.49 \%$ which corresponds to an absolute deviation of approximately $200 \mathrm{MHz}$ (see Tab. 1, Calc I). The ground state constants derived experimentally cannot however be directly compared to the computed $a b$ initio constants at equilibrium. In the case of $c i s$ methyl formate molecule $\mathrm{HCOOCH}_{3}$, another molecule containing an internal rotor, the theoretical vibration-rotation interaction $\alpha$ constants deduced from the ab initio cubic force field were combined with the known experimental ground state rotational constants to yield the semiexperimental equilibrium rotational constants to be compared with the equilibrium constants. The correction did not exceed $1.5 \%$ for methyl formate [11], thus less than the $2.49 \%$ observed in the case of allyl acetate. In order to obtain a better agreement between the observed and the ab initio rotational constants, we rotated the molecular fragment around $\varphi$ with a step width of $1^{\circ}$ and tried to find the angle where the deviation of the rotational constants becomes a minimum. We found that at $\varphi=129^{\circ}$ the deviations of $\mathrm{A}, \mathrm{B}$, and $\mathrm{C}$ are below $0.5 \%$ (see Tab. 2, Calc II). The difference of approximately $7.5^{\circ}$ is probably due to the small torsional force constant causing a rather flat minimum. Here very small interactions between both molecular fragments might cause rather large changes in $\varphi$. Maybe here a much better quantum chemical method and a larger basis set might increase accuracy by treating these small interactions more correctly. Also the angles between the internal rotor axis and the principal axes of inertia are improved by this empirical correction.

Finally it should be mentioned that only about $50 \%$ of all measured lines could be assigned. The still unassigned lines might be due to the planar conformer IV. Also some lines probably arise from isotopologues of strong lines of the assigned conformer. However, due to the complexity of the spectrum, none of these species could be presently assigned. 


\section{Acknowledgement}

We thank the Center for Computing and Communication of the RWTH Aachen University for free computer time and the Land Nordrhein-Westfalen for funds. We also thank the associated European laboratory LEA HiRes, which supported contacts between our groups in Créteil and in Aachen. 


\section{References}

[1] D. Jelisavac, D. Cortés Gómez, H.V.L. Nguyen, L.W. Sutikdja, W. Stahl, and I. Kleiner, J. Mol. Spectrosc. 257,111 (2009).

[2] J. Sheridan, W. Bossert, and A. Bauder, J. Mol. Spectrosc. 80, 1 (1980).

[3] U. Andresen, H. Dreizler, J.-U. Grabow, and W. Stahl, Rev. Sci. Instrum. 61, 3694 (1990).

[4] J.-U. Grabow, W. Stahl, and H. Dreizler, Rev. Sci. Instrum. 67, 4072 (1996).

[5] I. Merke, W. Stahl, and H. Dreizler, Z. Naturforsch. 49a, 490 (1994).

[6] Gaussian 03, Revision D.02, M. J. Frisch, G. W. Trucks, H. B. Schlegel, G. E. Scuseria, M. A. Robb, J. R. Cheeseman, J. A. Montgomery, Jr., T. Vreven, K. N. Kudin, J. C. Burant, J. M. Millam, S. S. Iyengar, J. Tomasi, V. Barone, B. Mennucci, M. Cossi, G. Scalmani, N. Rega, G. A. Petersson, H. Nakatsuji, M. Hada, M. Ehara, K. Toyota, R. Fukuda, J. Hasegawa, M. Ishida, T. Nakajima, Y. Honda, O. Kitao, H. Nakai, M. Klene, X. Li, J. E. Knox, H. P. Hratchian, J. B. Cross, V. Bakken, C. Adamo, J. Jaramillo, R. Gomperts, R. E. Stratmann, O. Yazyev, A. J. Austin, R. Cammi, C. Pomelli, J. W. Ochterski, P. Y. Ayala, K. Morokuma, G. A. Voth, P. Salvador, J. J. Dannenberg, V. G. Zakrzewski, S. Dapprich, A. D. Daniels, M. C. Strain, O. Farkas, D. K. Malick, A. D. Rabuck, K. Raghavachari, J. B. Foresman, J. V. Ortiz, Q. Cui, A. G. Baboul, S. Clifford, J. Cioslowski, B. B. Stefanov, G. Liu, A. Liashenko, P. Piskorz, I. Komaromi, R. L. Martin, D. J. Fox, T. Keith, M. A. AlLaham, C. Y. Peng, A. Nanayakkara, M. Challacombe, P. M. W. Gill, B. Johnson, W. Chen, M. W. Wong, C. Gonzalez, and J. A. Pople, Gaussian, Inc., Wallingford CT, 2004.

[7] H. Hartwig and H. Dreizler, Z. Naturforsch. 51a, 923 (1996).

[8] I. Kleiner and J. T. Hougen, J. Chem. Phys. 119, 5505 (2003).

[9] R. J. Lavrich, A. R. Hight Walker, D. F. Plusquellic, I. Kleiner, R. D. Suenram , J. T. Hougen and G. T. Fraser, J. Chem. Phys. 119, 5497 (2003).

[10] D. F. Plusquellic , I. Kleiner, J. Demaison, R. D. Suenram, R. J. Lavrich, F. J. Lovas, G. T. Fraser, V. V. Ilyushin, J. Chem. Phys. 125, 104312 (2006).

[11] J. Demaison, L. Margulès, I. Kleiner, and A.G. Császár, accepted in J. Mol. Spectrosc. 


\section{Tables}

Table 1: Rotational constants, stabilization energies, and dipole moments obtained from $a b$ initio calculations.

\begin{tabular}{|c|c|c|c|c|c|}
\hline \multicolumn{2}{|c|}{ Conformation } & $\begin{array}{c}\text { I } \\
\text { unstable }\end{array}$ & $\begin{array}{l}\mathrm{II}^{\prime} / \mathrm{III}{ }^{\mathrm{a}} \\
\text { stable }\end{array}$ & $\begin{array}{l}\text { II/III corrected } \\
\text { stable }\end{array}$ & $\begin{array}{c}\text { IV } \\
\text { stable }\end{array}$ \\
\hline$\varphi^{c}$ & $\circ$ & 180.0 & \pm 121.57 & 129.0 & 0.0 \\
\hline A & $\mathrm{GHz}$ & 8.370 & 7.698 & 7.511 & 6.164 \\
\hline B & $\mathrm{GHz}$ & 1.237 & 1.266 & 1.277 & 1.514 \\
\hline $\mathrm{C}$ & $\mathrm{GHz}$ & 1.092 & 1.137 & 1.150 & 1.234 \\
\hline Energy ${ }^{d}$ & $\mathrm{~kJ} / \mathrm{mol}$ & 9.879 & 0.000 & 0.280 & 2.595 \\
\hline$\left|\mu_{\mathrm{a}}\right|^{\mathrm{e}}$ & Debye & 0.499 & & 0.713 & 0.958 \\
\hline$\left|\mu_{b}\right|$ & Debye & 1.902 & & 1.908 & 1.636 \\
\hline$\left|\mu_{c}\right|$ & Debye & 0.000 & & 0.058 & 0.001 \\
\hline
\end{tabular}

${ }^{\text {a }}$ II and III are chiral enantiomers which cannot be distinguished by FTMW spectroscopy

${ }^{\mathrm{b}}$ Empirical correction by adjusting the dihedral angle $\varphi$ for best agreement with experimental rotational constants, see text.

${ }^{c}$ Dihedral angle $\varphi=\angle\left(\mathrm{O}_{3}-\mathrm{C}_{8}-\mathrm{C}_{11}-\mathrm{C}_{12}\right)$

${ }^{\mathrm{d}}$ Stabilization energies calculated at MP2/6-311++G** level with respect to the lowest energy conformers II/III at -344.917772 Hartree.

${ }^{\mathrm{e}}$ dipole moments in principal inertial axes 
Table 2: Molecular constants in the RAM system of allyl acetate obtained by a global fit using program BELGI-C . $_{\text {. }}$

\begin{tabular}{lllc}
\hline Operator $^{\mathrm{a}}$ & Constant $^{\mathbf{b}}$ & Unit $^{\mathrm{c}}$ & \multicolumn{1}{c}{ Value } \\
\hline $\mathrm{P}_{\mathrm{a}}{ }^{2}$ & $\mathrm{~A}$ & $\mathrm{GHz}$ & $7.51535(31)$ \\
$\mathrm{P}_{\mathrm{b}}{ }^{2}$ & $\mathrm{~B}$ & $\mathrm{GHz}$ & $1.14266690(55)$ \\
$\mathrm{P}_{\mathrm{c}}{ }^{2}$ & $\mathrm{C}$ & $\mathrm{GHz}$ & $1.4324355(43)$ \\
$\left\{\mathrm{P}_{\mathrm{a}}, \mathrm{P}_{\mathrm{c}}\right\}$ & $\mathrm{D}_{\mathrm{ac}}$ & $\mathrm{GHz}$ & $1.011141(13)$ \\
$-\mathrm{P}^{4}$ & $\Delta_{\mathrm{J}}$ & $\mathrm{kHz}$ & $0.19522(16)$ \\
$-\mathrm{P}^{2} \mathrm{P}_{\mathrm{a}}{ }^{2}$ & $\Delta_{\mathrm{JK}}$ & $\mathrm{kHz}$ & $-4.1206(37)$ \\
$-\mathrm{P}_{\mathrm{a}}{ }^{2}$ & $\Delta_{\mathrm{K}}$ & $\mathrm{kHz}$ & $33.975(51)$ \\
$-2 \mathrm{P}^{2}\left(\mathrm{P}_{\mathrm{b}}{ }^{2}-\mathrm{P}_{\mathrm{c}}{ }^{2}\right)$ & $\delta_{\mathrm{J}}$ & $\mathrm{kHz}$ & $-0.03006(13)$ \\
$-\left[\mathrm{P}_{\mathrm{a}}{ }^{2},\left(\mathrm{P}_{\mathrm{b}}{ }^{2}-\mathrm{P}_{\mathrm{c}}{ }^{2}\right)\right]$ & $\delta_{\mathrm{K}}$ & $\mathrm{kHz}$ & $0.6391(48)$ \\
$\mathrm{P}_{\gamma}{ }^{2}$ & $\mathrm{~F}$ & $\mathrm{GHz}$ & $160.61(19)$ \\
& & $\mathrm{cm}$ & $5.3575(62)$ \\
$(1 / 2)(1-\cos 3 \gamma)$ & $\mathrm{V}_{3}$ & $\mathrm{GHz}$ & $2955.3(44)$ \\
& & $\mathrm{cm}$ & $98.58(15)$ \\
$\mathrm{P}_{\mathrm{a}} \mathrm{P}_{\gamma}$ & $\rho$ & $\mathrm{unitless}$ & $0.035007(18)$ \\
$(1-\cos 3 \gamma) \mathrm{P}_{\mathrm{a}}{ }^{2}$ & $\mathrm{k}_{5}$ & $\mathrm{MHz}$ & $71.55(87)$ \\
$(1-\cos 3 \gamma) \mathrm{P}^{2}$ & $\mathrm{~F}_{\mathrm{V}}$ & $\mathrm{MHz}$ & $-1.6286(59)$ \\
$(1-\cos 3 \gamma)\left(\mathrm{P}_{\mathrm{b}}{ }^{2}-\mathrm{P}_{\mathrm{c}}{ }^{2}\right)$ & $\mathrm{c}_{2}$ & $\mathrm{MHz}$ & $0.7132(61)$ \\
$(1-\cos 3 \gamma)\left\{\mathrm{P}_{\mathrm{a}}, \mathrm{P}_{\mathrm{b}}\right\}$ & $\mathrm{d}_{\mathrm{ab}}$ & $\mathrm{MHz}$ & $5.5(56)$ \\
$(1-\cos 3 \gamma)\left\{\mathrm{P}_{\mathrm{a}}, \mathrm{P}_{\mathrm{c}}\right\}$ & $\mathrm{d}_{\mathrm{ac}}$ & $\mathrm{MHz}$ & $3.857(36)$ \\
& $\mathrm{N}_{\mathrm{A}} / \mathrm{N}_{\mathrm{E}} / \mathrm{N}_{\text {tot }}$ & & $109 / 62 / 171$ \\
& $\sigma_{\mathrm{A}} / \sigma_{\mathrm{E}} / \sigma_{\text {tot }}$ & $\mathrm{kHz}$ & $2.7 / 1.2 / 2.3$ \\
\hline \hline
\end{tabular}

${ }^{a}$ All constants refer to a rho-axis system, therefore the inertia tensor is not diagonal and the constants cannot be directly compared to those of a principal inertial axis system. $\mathrm{P}_{\mathrm{a}}, \mathrm{P}_{\mathrm{b}}, \mathrm{P}_{\mathrm{c}}$ are the components of the overall rotation angular momentum, $\mathrm{P}_{\gamma}$ is the angular momentum of the internal rotor rotating around the internal rotor axis by an angle $\gamma .\{\mathrm{u}, \mathrm{v}\}$ is the anti commutator $\mathrm{uv}+\mathrm{vu}$.

${ }^{\mathrm{b}}$ The product of the parameter and operator from a given row yields the term actually used in the vibration-rotation-torsion Hamiltonian, except for F, $\rho$, and $\mathrm{A}$, which occur in the Hamiltonian in the form $\mathrm{F}\left(\mathrm{P}_{\gamma}-\rho \mathrm{P}_{\mathrm{a}}\right)^{2}+\mathrm{AP}_{\mathrm{a}}{ }^{2}$.

$\mathrm{N}_{\mathrm{A}} / \mathrm{N}_{\mathrm{E}} / \mathrm{N}_{\text {tot }}$ are the numbers of $\mathrm{A}$ transitions, $\mathrm{E}$ transitions, and the total number of transitions. $\sigma_{\mathrm{A}} / \sigma_{\mathrm{E}} / \sigma_{\text {tot }}$ are the respective standard deviations.

${ }^{c}$ Values of the parameters from the present fit. Statistical uncertainties are shown as one standard uncertainty in the last digit. 
Table 3: Molecular constants in the PAM system of allyl acetate from different fits and $a b$ initio calculations.

\begin{tabular}{|c|c|c|c|c|c|c|c|c|c|c|}
\hline constant & unit & $\begin{array}{c}\text { Fit I } \\
\text { BELGI-C }_{1}\end{array}$ & $\begin{array}{c}\text { Fit II } \\
\text { XIAM }\end{array}$ & $\begin{array}{l}\text { Fit III } \\
\text { XIAM }\end{array}$ & Calc I $\mathbf{I}^{\mathrm{d}}$ & $\begin{array}{l}\text { Exp.- } \\
\text { Calc. }\end{array}$ & $\begin{array}{l}\text { Dev. } \\
{[\%]}\end{array}$ & Calc II $^{\mathbf{f}}$ & $\begin{array}{l}\text { Exp.- } \\
\text { Calc. }\end{array}$ & $\begin{array}{l}\text { Dev. } \\
{[\%]}\end{array}$ \\
\hline $\mathrm{A}$ & $\mathrm{GHz}$ & $7.67929(30)^{\mathrm{a}}$ & $7.7034352(67)$ & $7.70343360(35)$ & 7.511 & 0.192 & 2.49 & 7.698 & 0.005 & 0.06 \\
\hline $\mathrm{B}$ & $\mathrm{GHz}$ & $1.2691224(98)^{\mathrm{a}}$ & $1.2678319(59)$ & $1.267831492(71)$ & 1.277 & -0.009 & 0.71 & 1.266 & 0.002 & 0.15 \\
\hline $\mathrm{C}$ & $\mathrm{GHz}$ & $1.14203856(61)^{\mathrm{a}}$ & $1.1415254(63)$ & $1.141526125(76)$ & 1.150 & -0.008 & 0.79 & 1.137 & 0.005 & 0.43 \\
\hline$\Delta_{\mathrm{J}}$ & $\mathrm{kHz}$ & & $0.1399(34)$ & $0.13953(17)$ & & & & & & \\
\hline$\Delta_{\mathrm{JK}}$ & $\mathrm{kHz}$ & & $-1.195(33)$ & $-1.1808(18)$ & & & & & & \\
\hline$\Delta_{\mathrm{K}}$ & $\mathrm{kHz}$ & & $32.56(62)$ & $32.337(32)$ & & & & & & \\
\hline$\delta_{J}$ & $\mathrm{kHz}$ & & $0.0045(24)$ & $0.00246(13)$ & & & & & & \\
\hline$\delta_{\mathrm{K}}$ & $\mathrm{kHz}$ & & $-0.41(35)$ & $-0.392(18)$ & & & & & & \\
\hline $\mathrm{D}_{\text {pi2J }}$ & $\mathrm{kHz}$ & & $87.34(85)$ & 87.34 (fixed) & & & & & & \\
\hline $\mathrm{D}_{\mathrm{pi2}-}$ & $\mathrm{kHz}$ & & $47.89(93)$ & 47.89 (fixed) & & & & & & \\
\hline $\mathrm{V}_{3}$ & $\mathrm{GHz}$ & $2955.3(44)$ & $2940.74(35)$ & $2940.74 \quad$ (fixed) & & & & & & \\
\hline & $\mathrm{kJ} / \mathrm{mol}$ & $1.1793(18)^{\mathrm{c}}$ & $1.17345(14)$ & & & & & & & \\
\hline & $\mathrm{cm}^{-1}$ & $98.58(15)^{\mathrm{c}}$ & $98.093(12)$ & & & & & & & \\
\hline $\mathrm{F}_{0}$ & $\mathrm{GHz}$ & $158.621(82)$ & $153.589(15)$ & 153.589 (fixed) & & & & & & \\
\hline $\mathrm{I}_{\gamma}$ & $\mathrm{u} \AA^{2}$ & $3.1861(17)^{b}$ & $3.29046(33)$ & 3.29046 (fixed) & & & & & & \\
\hline$\angle(\mathrm{i}, \mathrm{a})$ & $\circ$ & $44.45601(64)$ & $44.4871(33)$ & 44. 4871 (fixed) & 46.73 & -2.24 & & 45.73 & -1.24 & \\
\hline$\angle(\mathrm{i}, \mathrm{b})$ & $\circ$ & $134.15842(61)$ & $134.8143(57)$ & 134. 8143 (fixed) & 136.46 & -1.65 & & 135.43 & -0.62 & \\
\hline$\angle(\mathrm{i}, \mathrm{c})$ & $\circ$ & $85.68777(84)$ & $85.832(17)$ & 85.832 (fixed) & 86.04 & -0.21 & & 85.82 & 0.01 & \\
\hline$\sigma$ & $\mathrm{kHz}$ & 2.3 & 54.0 & 2.7 & & & & & & \\
\hline $\mathrm{N}_{\mathrm{A}} / \mathrm{N}_{\mathrm{E}}$ & & $109 / 62$ & $109 / 62$ & $109 / 0$ & & & & & & \\
\hline $\mathrm{N}_{\text {tot }}$ & & 171 & 171 & 109 & & & & & & \\
\hline
\end{tabular}

Note: All constants refer to the principal inertial axis system, for the centrifugal distortion constants Watson's A

reduction and a $\mathrm{I}^{\mathrm{r}}$ representations was used.

${ }^{a}$ Obtained by transformation from rho axis system to principal inertial axis system, see text.

${ }^{\mathrm{b}}$ Moment of inertia $\mathrm{I}_{\gamma}$ of the internal rotor, calculated from its rotational constant $\mathrm{F}_{0}$.

${ }^{\mathrm{c}}$ Hindering potential, calculated from value in frequency units.

${ }^{\mathrm{d}}$ Calculation on MP2/6-311++G** level using Gaussian 03. 


\section{Page 15 of 32}

\section{Molecular Physics}

${ }^{\mathrm{e}}$ With respect to Fit II
${ }^{\mathrm{f}}$ Same as Calc I with empirical correction, see text

URL: http://mc.manuscriptcentral.com/tandf/tmph 


\section{Figure Caption}

Fig. 1: A typical spectrum of allyl acetate.

The experimental resolution was $0.8 \mathrm{kHz}$, the typical experimental line width $8 \mathrm{kHz}$ as indicated in the spectrum. The large splitting is due to the Doppler effect. For this spectrum 60 FIDs were co-added.

Fig. 2: A typical scan of allyl acetate

The spectral range of $40 \mathrm{MHz}$ was covered by overlapping spectra with a step width of $250 \mathrm{kHz}$. For each single measure 50 FIDs were co-added.

Fig. 3: The planar conformer (conformer I) of allyl acetate

Fig. 4: The bent conformer (conformer II) of allyl acetate from Gaussians optimization. The dihedral angel $\mathrm{O}_{3}-\mathrm{C}_{8}-\mathrm{C}_{11}-\mathrm{C}_{12}$ is $121.57^{\circ}$.

Fig. 5: The minimum energy path of allyl acetate obtained by rotating the ethylene group. For all dihedral angles $\varphi$ all other structural parameters were allowed to relaxe. The relative energy with respect to the lowest energy conformers II/III is given. Conformer III is the enantiomer of conformer II with the same rotational constants.

Fig. 6: Comparison of the calculated rotational constants (A, B, C) for different dihedral angel $\varphi$ with the experimental rotational constants $\left(\mathrm{A}_{\exp }, \mathrm{B}_{\exp }, \mathrm{C}_{\exp }\right)$.

The A rotational constant is described at the left scale and the $\mathrm{B}$ and $\mathrm{C}$ rotational constants at the right scale. The horizontal lines are the experimental rotational constants. The vertical lines show the position where the calculated and the experimental data have the best agreement. 
Fig. 1

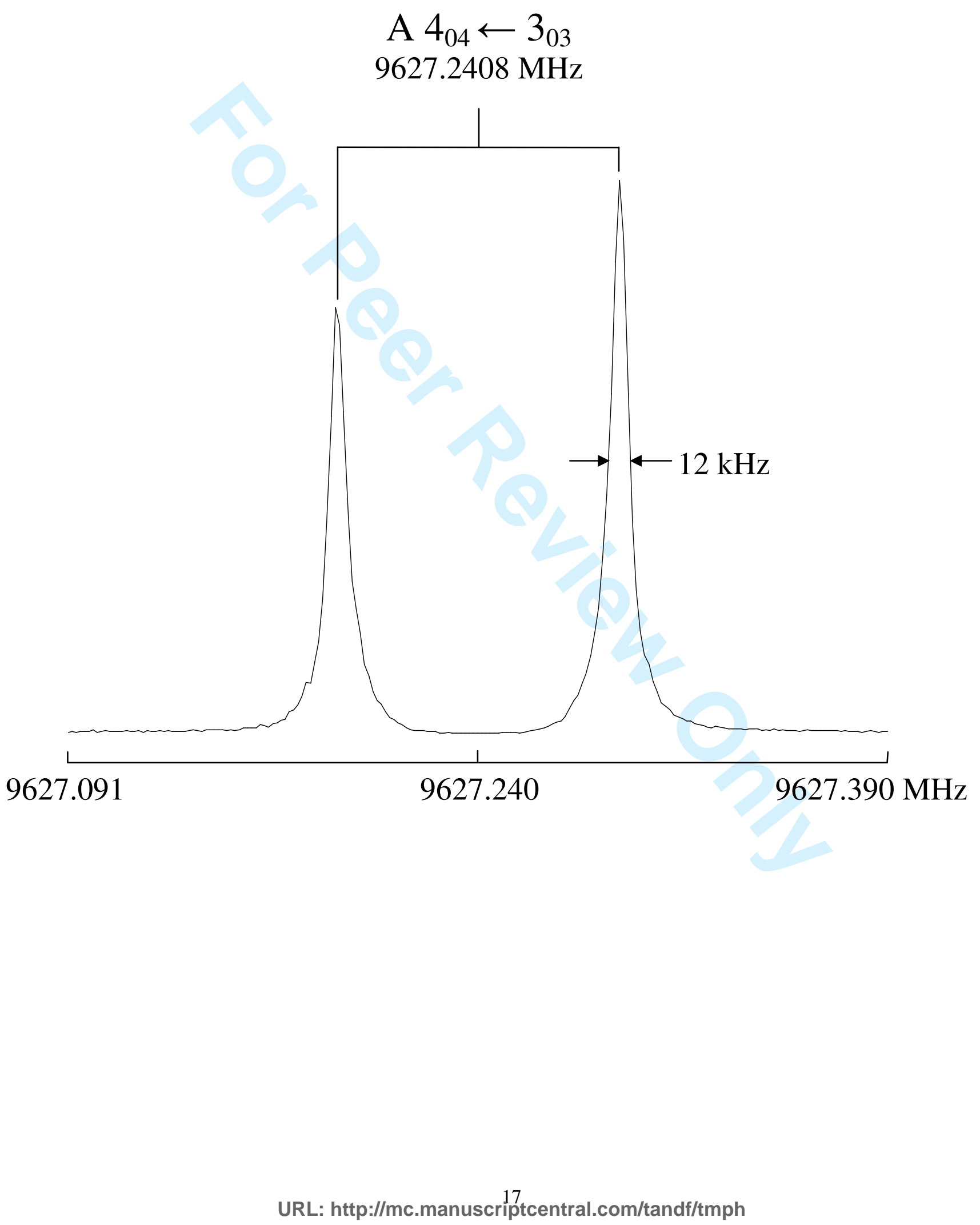


Fig. 2

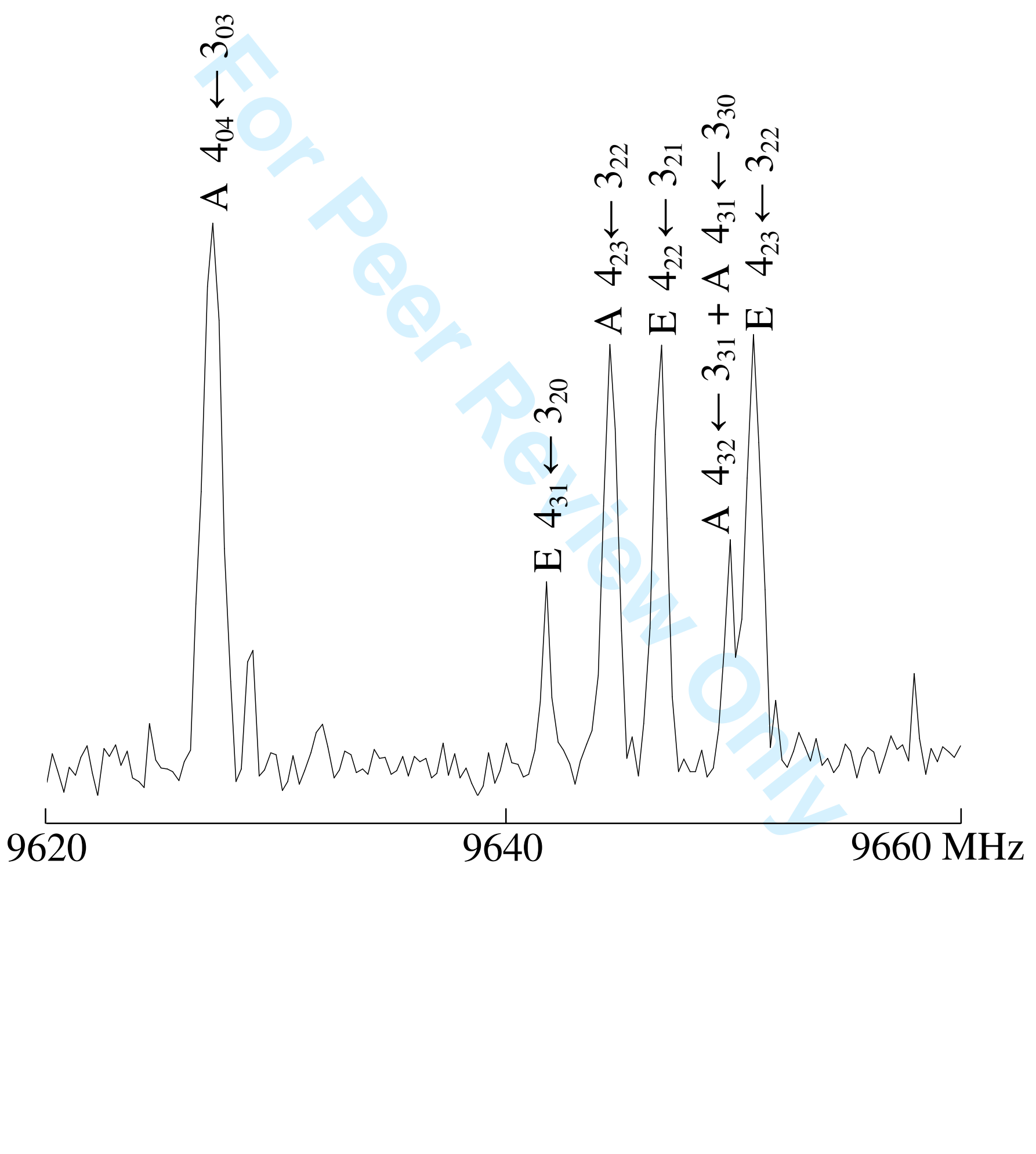

URL: http://mc.manuscriptcentral.com/tandf/tmph 


\section{Page 19 of 32}

Fig. 3

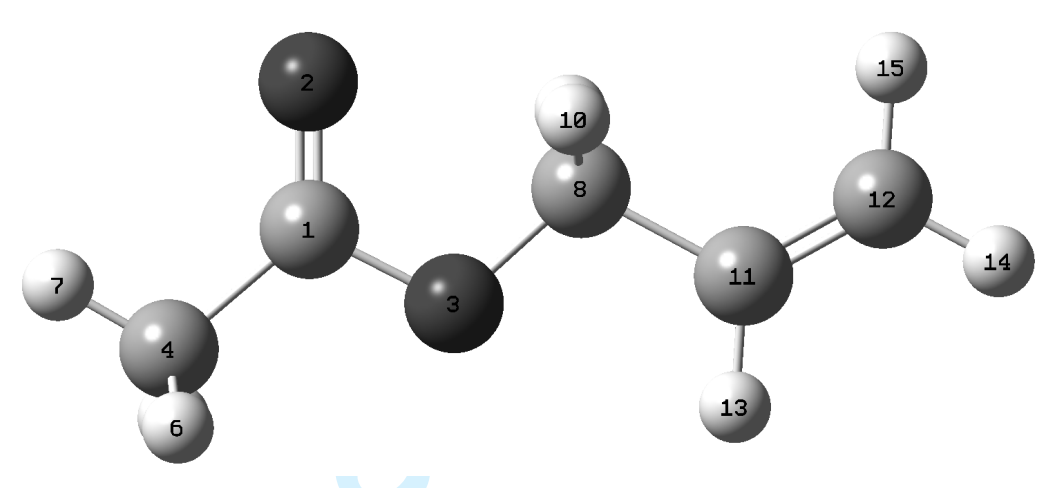

2

5

6

7

10

11

12 
Fig. 4

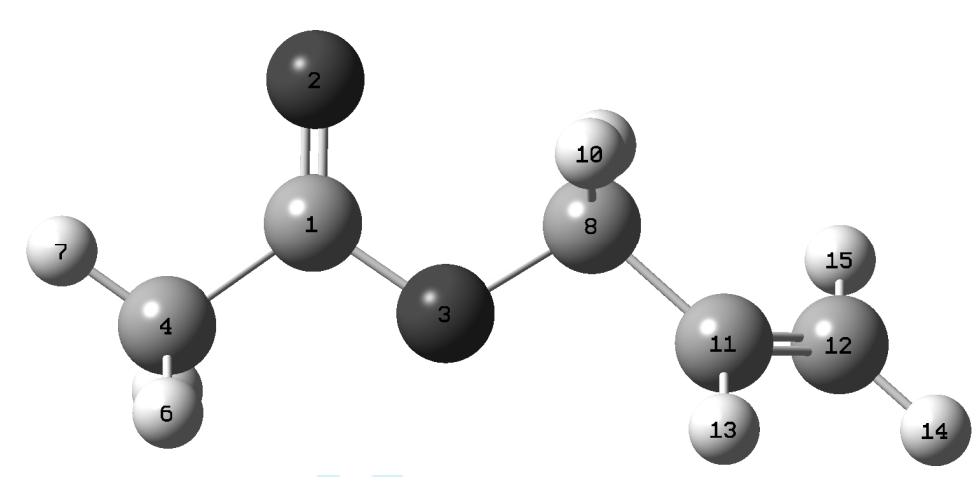

17

18

19

20

21

22

23

24

25

26

27

28

29

30

31

32

33

34

35

36

37

38

39

40

41

42

43

44

45

46

47

48

49

50

51

52

53

54

55

56

57

58

59

60 
Fig. 5

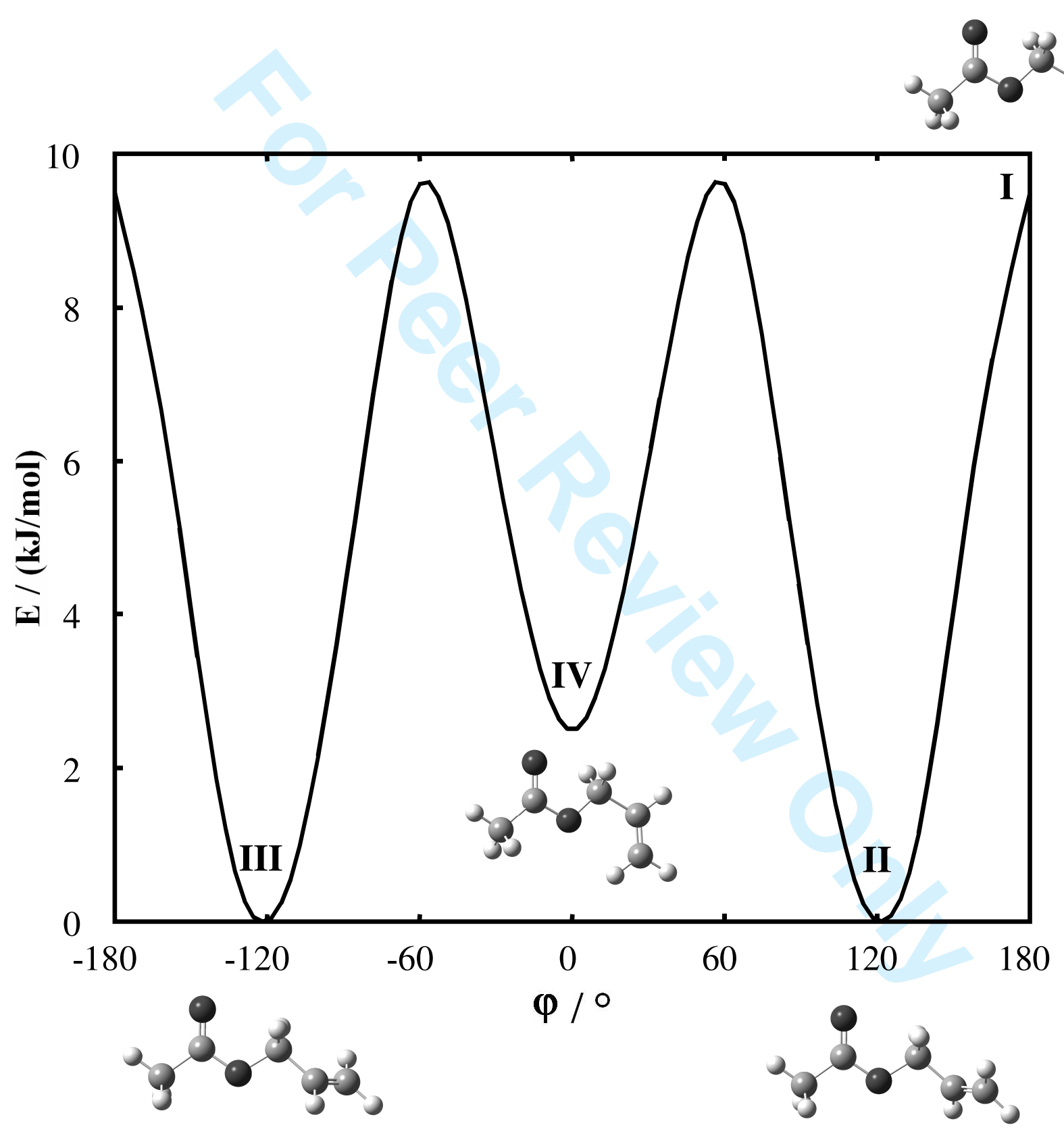

URL: http://mc.manuscriptcentral.com/tandf/tmph 
Fig. 6

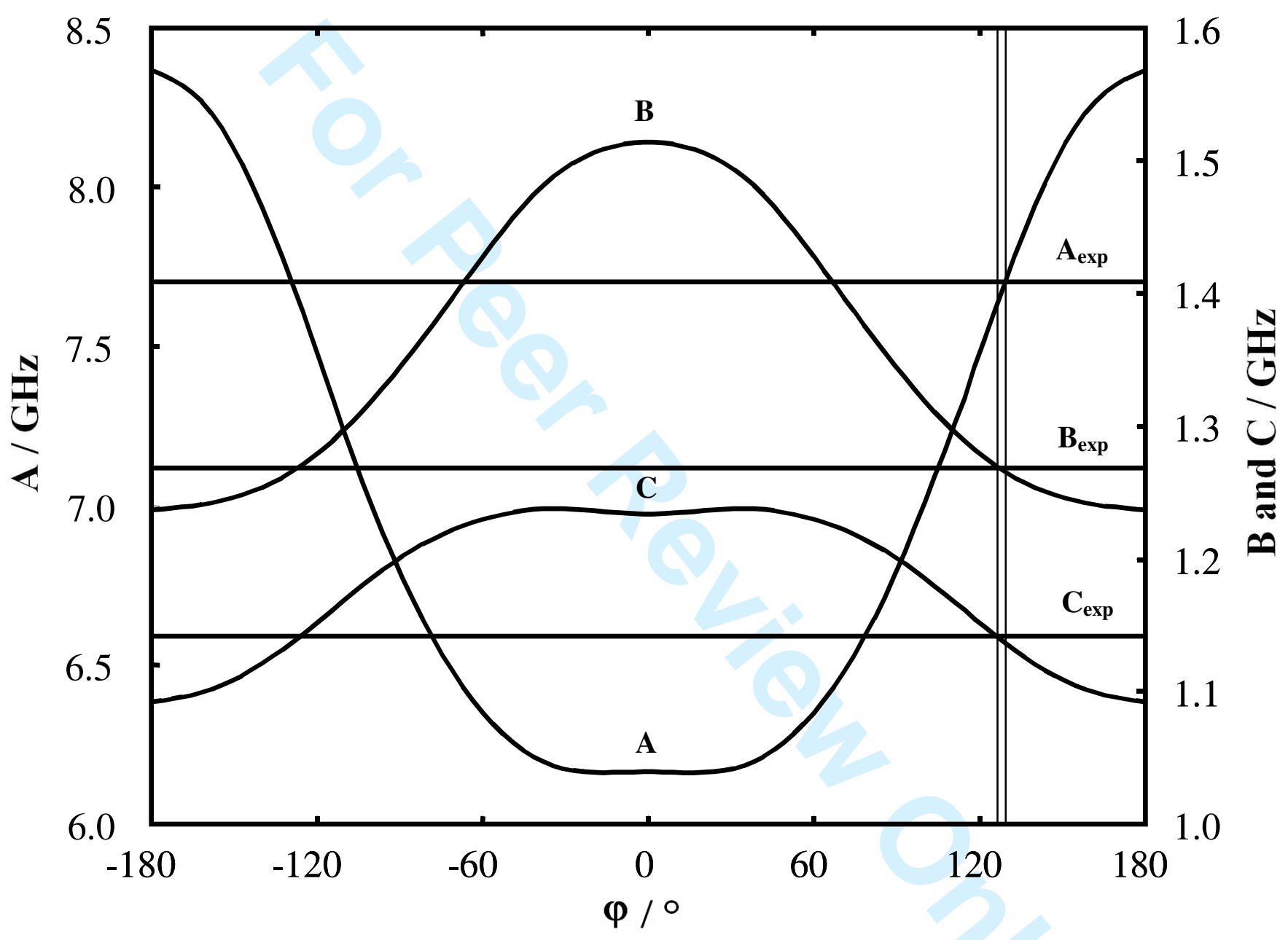




\title{
Supplementary data
}

\section{The Microwave Spectrum of Allyl Acetate}

\author{
H.V.L. Nguyen ${ }^{\mathrm{a}}$, H. Mouhib ${ }^{\mathrm{a}}$, W.Stahl ${ }^{\mathrm{a}}$, and I. Kleiner ${ }^{\mathrm{b}}$ \\ ${ }^{\text {a }}$ Institute of Physical Chemistry, RWTH Aachen University, Landoltweg 2, D-52074 Aachen, \\ Germany \\ ${ }^{\mathrm{b}}$ Laboratoire Interuniversitaire des Systèmes Atmosphériques (LISA), UMR 7583 \\ (CNRS/Univ. Paris 12 \& Paris 7), Université de Paris 12, 61 avenue du Général de Gaulle, F- \\ 94010 Créteil cedex, France
}


TABLE S1: Observed A species frequencies (obs) of allyl acetate and obs-calc values after fit with BELGI-C ${ }_{1}$.

\begin{tabular}{|c|c|c|c|c|c|c|c|}
\hline \multicolumn{3}{|c|}{$\begin{array}{c}\mathbf{J} \mathbf{K}_{\mathbf{a}} \mathbf{K}_{\mathbf{c}} \\
\text { upper level }\end{array}$} & \multicolumn{3}{|c|}{$\begin{array}{l}\mathbf{J} \quad \mathbf{K}_{\mathbf{a}} \mathbf{K}_{\mathbf{c}} \\
\text { lower level }\end{array}$} & \multirow{2}{*}{$\begin{array}{l}\begin{array}{c}\text { obs } \\
\mathrm{MHz}\end{array} \\
8899.210\end{array}$} & \multirow{2}{*}{$\begin{array}{c}\begin{array}{c}\text { obs-calc } \\
\mathrm{MHz}\end{array} \\
-0.001\end{array}$} \\
\hline 1 & 1 & 1 & 0 & 0 & 0 & & \\
\hline 3 & 2 & 2 & 4 & 1 & 3 & 9373.292 & 0.000 \\
\hline 4 & 1 & 4 & 3 & 1 & 3 & 9386.164 & 0.001 \\
\hline 4 & 0 & 4 & 3 & 0 & 3 & 9627.241 & 0.000 \\
\hline 4 & 2 & 3 & 3 & 2 & 2 & 9644.523 & 0.001 \\
\hline 4 & 3 & 2 & 3 & 3 & 1 & 9649.679 & 0.000 \\
\hline 4 & 3 & 1 & 3 & 3 & 0 & 9649.783 & 0.001 \\
\hline 4 & 2 & 2 & 3 & 2 & 1 & 9663.270 & 0.000 \\
\hline 9 & 1 & 8 & 9 & 0 & 9 & 9887.376 & 0.001 \\
\hline 4 & 1 & 3 & 3 & 1 & 2 & 9898.300 & -0.001 \\
\hline 3 & 2 & 1 & 4 & 1 & 4 & 10663.163 & 0.005 \\
\hline 2 & 1 & 2 & 1 & 0 & 1 & 11182.648 & -0.003 \\
\hline 8 & 3 & 5 & 9 & 2 & 8 & 11201.637 & 0.002 \\
\hline 5 & 1 & 5 & 4 & 1 & 4 & 11729.275 & 0.001 \\
\hline 5 & 0 & 5 & 4 & 0 & 4 & 12020.039 & 0.001 \\
\hline 2 & 2 & 1 & 3 & 1 & 2 & 12037.091 & -0.003 \\
\hline 5 & 2 & 4 & 4 & 2 & 3 & 12053.282 & 0.001 \\
\hline 5 & 4 & 2 & 4 & 4 & 1 & 12061.602 & -0.001 \\
\hline 5 & 4 & 1 & 4 & 4 & 0 & 12061.602 & -0.002 \\
\hline 5 & 3 & 3 & 4 & 3 & 2 & 12063.718 & 0.000 \\
\hline 5 & 3 & 2 & 4 & 3 & 1 & 12064.078 & 0.000 \\
\hline 5 & 2 & 3 & 4 & 2 & 2 & 12090.701 & -0.001 \\
\hline 5 & 1 & 4 & 4 & 1 & 3 & 12369.212 & -0.001 \\
\hline 7 & 3 & 5 & 8 & 2 & 6 & 13162.001 & 0.001 \\
\hline 3 & 1 & 3 & 2 & 0 & 2 & 13402.767 & -0.001 \\
\hline 7 & 3 & 4 & 8 & 2 & 7 & 13554.565 & 0.001 \\
\hline 6 & 0 & 6 & 5 & 0 & 5 & 14403.657 & 0.001 \\
\hline 6 & 2 & 5 & 5 & 2 & 4 & 14460.461 & 0.000 \\
\hline 6 & 5 & 1 & 5 & 5 & 0 & 14473.555 & 0.001 \\
\hline 6 & 5 & 2 & 5 & 5 & 1 & 14473.555 & 0.001 \\
\hline 6 & 4 & 3 & 5 & 4 & 2 & 14475.263 & 0.002 \\
\hline 6 & 4 & 2 & 5 & 4 & 1 & 14475.263 & -0.003 \\
\hline 6 & 3 & 4 & 5 & 3 & 3 & 14478.743 & 0.000 \\
\hline 6 & 3 & 3 & 5 & 3 & 2 & 14479.706 & 0.001 \\
\hline 6 & 2 & 4 & 5 & 2 & 3 & 14525.713 & 0.000 \\
\hline 4 & 1 & 4 & 3 & 0 & 3 & 15561.932 & -0.002 \\
\hline 7 & 5 & 3 & 6 & 5 & 2 & 16886.945 & -0.002 \\
\hline 7 & 5 & 2 & 6 & 5 & 1 & 16886.945 & -0.002 \\
\hline 7 & 4 & 4 & 6 & 4 & 3 & 16889.637 & -0.010 \\
\hline 7 & 4 & 3 & 6 & 4 & 2 & 16889.672 & 0.010 \\
\hline 7 & 3 & 5 & 6 & 3 & 4 & 16894.861 & -0.001 \\
\hline 7 & 3 & 4 & 6 & 3 & 3 & 16897.025 & 0.000 \\
\hline 9 & 0 & 9 & 8 & 1 & 8 & 16935.998 & -0.002 \\
\hline
\end{tabular}


TABLE S1 cntd. Observed A species frequencies of allyl acetate.

\begin{tabular}{|c|c|c|c|c|c|c|c|}
\hline & & $\begin{array}{r}\mathbf{K}_{\mathbf{c}} \\
\text { vel }\end{array}$ & & $\begin{array}{l}\mathbf{K}_{\mathbf{a}} \\
\text { er } 1\end{array}$ & $\begin{array}{l}\mathbf{K}_{\mathbf{c}} \\
\mathrm{vel}\end{array}$ & $\begin{array}{c}\text { obs } \\
\mathrm{MHz}\end{array}$ & $\begin{array}{c}\text { obs-calc } \\
\mathrm{MHz}\end{array}$ \\
\hline 7 & 1 & 6 & 6 & 1 & 5 & 17302.818 & 0.000 \\
\hline 9 & 2 & 7 & 9 & 1 & 8 & 17447.225 & 0.001 \\
\hline 5 & 1 & 5 & 4 & 0 & 4 & 17663.965 & -0.003 \\
\hline 8 & 2 & 6 & 8 & 1 & 7 & 17781.213 & 0.000 \\
\hline 8 & 1 & 8 & 7 & 1 & 7 & 18744.102 & -0.001 \\
\hline 5 & 2 & 3 & 5 & 1 & 4 & 18767.434 & 0.000 \\
\hline 4 & 2 & 2 & 4 & 1 & 3 & 19045.941 & -0.003 \\
\hline 3 & 2 & 1 & 3 & 1 & 2 & 19280.973 & -0.003 \\
\hline 8 & 6 & 3 & 7 & 6 & 2 & 19298.738 & 0.003 \\
\hline 8 & 6 & 2 & 7 & 6 & 1 & 19298.738 & 0.003 \\
\hline 8 & 5 & 3 & 7 & 5 & 2 & 19300.866 & 0.001 \\
\hline 8 & 5 & 4 & 7 & 5 & 3 & 19300.866 & 0.001 \\
\hline 8 & 4 & 5 & 7 & 4 & 4 & 19304.883 & 0.005 \\
\hline 8 & 4 & 4 & 7 & 4 & 3 & 19304.918 & -0.003 \\
\hline 8 & 3 & 6 & 7 & 3 & 5 & 19312.137 & 0.003 \\
\hline 8 & 3 & 5 & 7 & 3 & 4 & 19316.453 & -0.002 \\
\hline 2 & 2 & 0 & 2 & 1 & 1 & 19464.381 & -0.001 \\
\hline 8 & 1 & 7 & 7 & 1 & 6 & 19764.250 & 0.000 \\
\hline 2 & 2 & 1 & 2 & 1 & 2 & 19846.686 & 0.000 \\
\hline 3 & 2 & 2 & 3 & 1 & 3 & 20039.941 & 0.003 \\
\hline 4 & 2 & 3 & 4 & 1 & 4 & 20298.299 & 0.002 \\
\hline 5 & 2 & 4 & 5 & 1 & 5 & 20622.305 & 0.001 \\
\hline 2 & 2 & 1 & 1 & 1 & 0 & 24413.570 & -0.001 \\
\hline 2 & 2 & 0 & 1 & 1 & 1 & 24543.508 & -0.002 \\
\hline 10 & 1 & 10 & 9 & 0 & 9 & 27546.250 & 0.000 \\
\hline 13 & 0 & 13 & 12 & 1 & 12 & 27827.837 & -0.001 \\
\hline 11 & 1 & 11 & 10 & 0 & 10 & 29457.917 & 0.004 \\
\hline 14 & 0 & 14 & 13 & 1 & 13 & 30492.182 & -0.005 \\
\hline 5 & 2 & 4 & 4 & 1 & 3 & 31071.094 & -0.002 \\
\hline 13 & 3 & 10 & 13 & 2 & 11 & 31194.122 & -0.004 \\
\hline 13 & 2 & 12 & 12 & 2 & 11 & 31240.482 & -0.004 \\
\hline 13 & 4 & 10 & 12 & 4 & 9 & 31397.523 & -0.001 \\
\hline 13 & 4 & 9 & 12 & 4 & 8 & 31399.013 & 0.004 \\
\hline 13 & 3 & 11 & 12 & 3 & 10 & 31414.015 & 0.000 \\
\hline 13 & 3 & 10 & 12 & 3 & 9 & 31464.503 & 0.003 \\
\hline 12 & 3 & 9 & 12 & 2 & 10 & 31568.823 & -0.001 \\
\hline 13 & 2 & 11 & 12 & 2 & 10 & 31839.203 & 0.006 \\
\hline 11 & 3 & 8 & 11 & 2 & 9 & 31881.966 & -0.002 \\
\hline 13 & 1 & 12 & 12 & 1 & 11 & 31986.666 & 0.002 \\
\hline 10 & 3 & 7 & 10 & 2 & 8 & 32135.379 & -0.001 \\
\hline 9 & 3 & 6 & 9 & 2 & 7 & 32333.364 & 0.002 \\
\hline 5 & 2 & 3 & 4 & 1 & 4 & 32417.130 & 0.001 \\
\hline 8 & 3 & 5 & 8 & 2 & 6 & 32482.065 & 0.003 \\
\hline 7 & 3 & 4 & 7 & 2 & 5 & 32588.785 & 0.004 \\
\hline 6 & 3 & 3 & 6 & 2 & 4 & 32661.306 & 0.002 \\
\hline
\end{tabular}


TABLE S1 cntd. Observed A species frequencies of allyl acetate.

\begin{tabular}{|c|c|c|c|c|c|c|c|}
\hline \multicolumn{3}{|c|}{$\begin{array}{lr}\mathbf{J} & \mathbf{K}_{\mathbf{a}} \\
\text { upper level } & \mathbf{K}_{\mathbf{c}}\end{array}$} & \multicolumn{3}{|c|}{$\begin{array}{l}\mathbf{J} \quad \mathbf{K}_{\mathbf{a}} \mathbf{K}_{\mathbf{c}} \\
\text { lower level }\end{array}$} & \multirow{2}{*}{$\begin{array}{c}\text { obs } \\
\text { MHz } \\
32687.731\end{array}$} & \multirow{2}{*}{$\begin{array}{c}\begin{array}{c}\text { obs-calc } \\
\mathrm{MHz}\end{array} \\
-0.001\end{array}$} \\
\hline 14 & 1 & 14 & 13 & 1 & 13 & & \\
\hline 5 & 3 & 2 & 5 & 2 & 3 & 32707.310 & -0.002 \\
\hline 4 & 3 & 1 & 4 & 2 & 2 & 32733.932 & -0.003 \\
\hline 3 & 3 & 0 & 3 & 2 & 1 & 32747.424 & 0.002 \\
\hline 4 & 3 & 2 & 4 & 2 & 3 & 32761.945 & 0.000 \\
\hline 5 & 3 & 3 & 5 & 2 & 4 & 32772.382 & 0.001 \\
\hline 6 & 3 & 4 & 6 & 2 & 5 & 32790.665 & 0.002 \\
\hline 7 & 3 & 5 & 7 & 2 & 6 & 32819.777 & -0.003 \\
\hline 8 & 3 & 6 & 8 & 2 & 7 & 32863.092 & 0.000 \\
\hline 9 & 3 & 7 & 9 & 2 & 8 & 32924.273 & 0.000 \\
\hline 10 & 3 & 8 & 10 & 2 & 9 & 33007.254 & -0.001 \\
\hline 14 & 0 & 14 & 13 & 0 & 13 & 33036.797 & -0.003 \\
\hline 11 & 3 & 9 & 11 & 2 & 10 & 33116.156 & -0.004 \\
\hline 6 & 2 & 5 & 5 & 1 & 4 & 33162.346 & 0.002 \\
\hline 12 & 3 & 10 & 12 & 2 & 11 & 33255.236 & 0.006 \\
\hline 13 & 1 & 13 & 12 & 0 & 12 & 33292.744 & 0.002 \\
\hline 13 & 3 & 11 & 13 & 2 & 12 & 33428.764 & 0.005 \\
\hline 14 & 3 & 12 & 14 & 2 & 13 & 33641.023 & -0.005 \\
\hline 15 & 3 & 13 & 15 & 2 & 14 & 33896.223 & -0.006 \\
\hline 14 & 1 & 14 & 13 & 0 & 13 & 35232.349 & 0.003 \\
\hline 9 & 2 & 8 & 8 & 1 & 7 & 39061.637 & -0.003 \\
\hline
\end{tabular}


TABLE S2: Observed E species frequencies (obs) of allyl acetate and obs-calc values after fit with BELGI-C .

\begin{tabular}{|c|c|c|c|c|c|c|c|}
\hline & $\begin{array}{l}\mathbf{K}_{\mathbf{a}} \\
\text { er le }\end{array}$ & & $\begin{array}{l}\mathbf{J} \\
\text { low }\end{array}$ & & & $\begin{array}{l}\text { obs } \\
\mathrm{MHz}\end{array}$ & $\begin{array}{c}\text { obs-calc } \\
\mathrm{MHz}\end{array}$ \\
\hline 1 & 1 & 1 & 0 & 0 & 0 & 7498.669 & -0.002 \\
\hline 6 & 0 & 6 & 5 & 1 & 5 & 9407.794 & 0.001 \\
\hline 4 & 1 & 4 & 3 & 1 & 3 & 9550.206 & 0.001 \\
\hline 4 & 0 & 4 & 3 & 0 & 3 & 9594.276 & 0.000 \\
\hline 4 & -2 & 2 & 3 & -2 & 1 & 9646.692 & 0.000 \\
\hline 4 & 2 & 3 & 3 & 2 & 2 & 9650.765 & 0.001 \\
\hline 8 & -1 & 7 & 8 & 0 & 8 & 9687.986 & 0.002 \\
\hline 4 & -1 & 3 & 3 & -1 & 2 & 9734.043 & -0.001 \\
\hline 2 & 1 & 2 & 1 & 0 & 1 & 9910.385 & -0.002 \\
\hline 2 & 2 & 1 & 3 & 1 & 3 & 10851.832 & 0.000 \\
\hline 3 & -2 & 1 & 4 & -1 & 3 & 11002.729 & 0.001 \\
\hline 5 & 1 & 5 & 4 & 1 & 4 & 11881.648 & 0.002 \\
\hline 5 & 0 & 5 & 4 & 0 & 4 & 11983.261 & -0.001 \\
\hline 5 & -4 & 1 & 4 & -4 & 0 & 12050.870 & 0.000 \\
\hline 5 & -3 & 2 & 4 & -3 & 1 & 12053.754 & 0.000 \\
\hline 5 & 4 & 2 & 4 & 4 & 1 & 12055.349 & -0.001 \\
\hline 5 & 3 & 3 & 4 & 3 & 2 & 12057.822 & 0.000 \\
\hline 5 & -2 & 3 & 4 & -2 & 2 & 12062.555 & 0.001 \\
\hline 5 & 2 & 4 & 4 & 2 & 3 & 12068.780 & 0.001 \\
\hline 5 & -1 & 4 & 4 & -1 & 3 & 12212.008 & 0.000 \\
\hline 3 & 1 & 3 & 2 & 0 & 2 & 12303.039 & -0.002 \\
\hline 2 & -1 & 1 & 1 & 0 & 1 & 12707.988 & -0.002 \\
\hline 2 & -2 & 0 & 3 & -1 & 2 & 13503.676 & 0.000 \\
\hline 9 & 2 & 8 & 9 & -1 & 8 & 13830.993 & 0.001 \\
\hline 8 & 2 & 7 & 8 & -1 & 7 & 14186.638 & 0.000 \\
\hline 6 & -4 & 2 & 5 & -4 & 1 & 14462.293 & 0.001 \\
\hline 6 & -3 & 3 & 5 & -3 & 2 & 14466.840 & 0.003 \\
\hline 6 & 4 & 3 & 5 & 4 & 2 & 14467.822 & -0.001 \\
\hline 6 & 3 & 4 & 5 & 3 & 3 & 14472.137 & 0.000 \\
\hline 6 & -2 & 4 & 5 & -2 & 3 & 14481.385 & 0.000 \\
\hline 7 & 2 & 6 & 7 & -1 & 6 & 14505.325 & 0.002 \\
\hline 4 & 1 & 4 & 3 & 0 & 3 & 14653.284 & 0.000 \\
\hline 5 & 2 & 4 & 5 & -1 & 4 & 14983.522 & 0.000 \\
\hline 3 & -1 & 2 & 2 & 0 & 2 & 15180.381 & -0.002 \\
\hline 7 & -5 & 2 & 6 & -5 & 1 & 16871.174 & 0.000 \\
\hline 7 & -4 & 3 & 6 & -4 & 2 & 16874.395 & 0.000 \\
\hline 7 & 5 & 3 & 6 & 5 & 2 & 16878.737 & 0.000 \\
\hline 7 & 3 & 5 & 6 & 3 & 4 & 16887.959 & 0.000 \\
\hline 5 & 1 & 5 & 4 & 0 & 4 & 16940.654 & 0.000 \\
\hline 9 & 0 & 9 & 8 & 1 & 8 & 17177.818 & -0.002 \\
\hline 7 & -1 & 6 & 6 & -1 & 5 & 17183.961 & 0.001 \\
\hline 2 & 2 & 1 & 2 & 1 & 2 & 18046.395 & 0.000 \\
\hline 3 & 2 & 2 & 3 & 1 & 3 & 18087.371 & 0.000 \\
\hline
\end{tabular}


TABLE S2 cntd. Observed E species frequencies of allyl acetate.

\begin{tabular}{rrrrrrcr}
\hline \multicolumn{5}{l}{$\mathbf{J}$} & $\mathbf{K}_{\mathbf{a}}$ & $\mathbf{K}_{\mathbf{c}}$ & \multicolumn{3}{l}{$\mathbf{J}$} & $\mathbf{K}_{\mathbf{a}}$ & $\mathbf{K}_{\mathbf{c}}$ & $\begin{array}{c}\text { obs } \\
\text { upper level }\end{array}$ & \multicolumn{1}{c}{$\begin{array}{c}\text { obs-calc level } \\
\text { MHz }\end{array}$} \\
\hline 4 & 2 & 3 & 4 & 1 & 4 & 18187.930 & 0.000 \\
5 & 2 & 4 & 5 & 1 & 5 & 18375.061 & -0.002 \\
8 & 1 & 8 & 7 & 1 & 7 & 18816.622 & 0.000 \\
10 & -2 & 8 & 10 & -1 & 9 & 18941.399 & -0.001 \\
8 & -5 & 3 & 7 & -5 & 2 & 19282.749 & 0.000 \\
8 & -4 & 4 & 7 & -4 & 3 & 19287.294 & 0.000 \\
8 & 4 & 5 & 7 & 4 & 4 & 19295.194 & -0.002 \\
8 & -3 & 5 & 7 & -3 & 4 & 19297.054 & 0.001 \\
8 & 3 & 6 & 7 & 3 & 5 & 19305.548 & -0.001 \\
9 & -2 & 7 & 9 & -1 & 8 & 19313.538 & -0.001 \\
8 & 2 & 7 & 8 & 1 & 8 & 19600.841 & -0.001 \\
10 & 0 & 10 & 9 & 1 & 9 & 19838.711 & 0.002 \\
5 & -2 & 3 & 5 & -1 & 4 & 20499.967 & 0.001 \\
4 & -2 & 2 & 4 & -1 & 3 & 20649.422 & 0.003 \\
3 & -2 & 1 & 3 & -1 & 2 & 20736.771 & 0.001 \\
2 & -2 & 0 & 2 & -1 & 1 & 20777.977 & 0.000 \\
2 & 2 & 1 & 1 & 1 & 1 & 22859.623 & 0.001 \\
3 & 2 & 2 & 2 & 1 & 2 & 25281.934 & 0.001 \\
2 & -2 & 0 & 1 & -1 & 0 & 25613.451 & -0.002 \\
\hline \hline
\end{tabular}

TABLE S3: Some $c$-type transitions of allyl acetate (not incl. in fit)

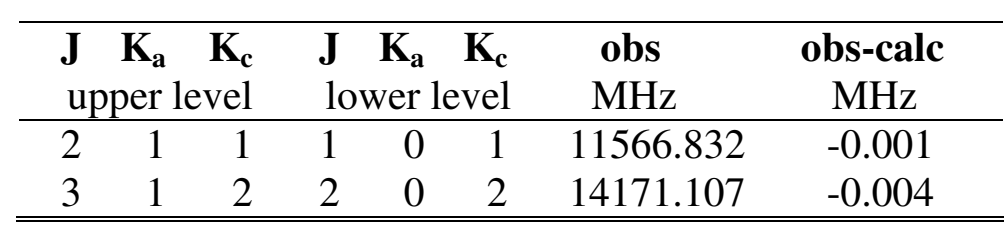


TABLE S4: Calculated geometry parameters in Gaussian [6] internal coordinate system (called standard orientation) of two stable trans conformers of allyl acetate found in the local minima of the potential energy surface by rotating around the $C_{8}-C_{11}$ bond. The atoms are numbered according the figure given below.

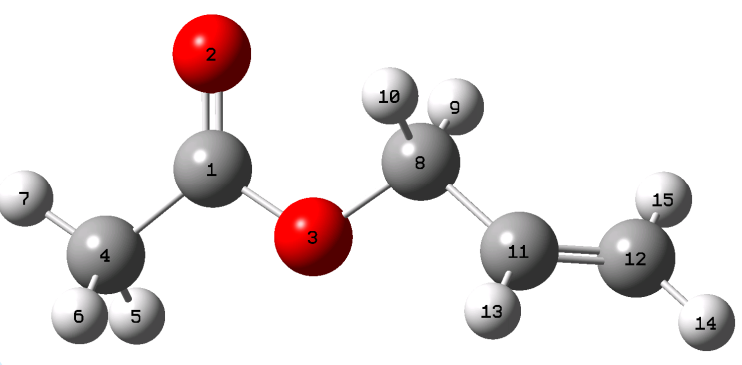

\begin{tabular}{|c|c|c|c|c|c|c|}
\hline & & Conformer & & & nformer IV & \\
\hline & $X$ & $\mathrm{Y}$ & $\mathrm{Z}$ & $\mathrm{X}$ & $\mathrm{Y}$ & $\mathrm{Z}$ \\
\hline 1 & 1.467027 & 0.122172 & 0.028940 & -1.384136 & -0.081511 & -0.000073 \\
\hline 2 & 1.655847 & 1.319410 & 0.036843 & -1.781536 & -1.226148 & -0.000143 \\
\hline 3 & 0.238421 & -0.438187 & -0.088803 & -0.070319 & 0.252789 & -0.000044 \\
\hline 4 & 2.523577 & -0.944881 & 0.150083 & -2.241211 & 1.156976 & 0.000081 \\
\hline 5 & 2.336801 & -1.543576 & 1.044724 & -2.017987 & 1.758321 & 0.884397 \\
\hline 6 & 2.476508 & -1.611091 & -0.714159 & -2.015491 & 1.760517 & -0.882084 \\
\hline 7 & 3.504815 & -0.476558 & 0.211904 & -3.291476 & 0.869218 & -0.001659 \\
\hline 8 & -0.843356 & 0.513339 & -0.211399 & 0.828933 & -0.864529 & 0.000126 \\
\hline 9 & -0.889045 & 1.133186 & 0.688789 & 0.634910 & -1.484995 & 0.882093 \\
\hline 10 & -0.638888 & 1.163776 & -1.067800 & 0.634935 & -1.485245 & -0.881669 \\
\hline 11 & -2.100655 & -0.27027 & -0.400640 & 2.240234 & -0.364963 & 0.000073 \\
\hline 12 & -3.150290 & -0.174671 & 0.427751 & 2.611762 & 0.922026 & -0.000108 \\
\hline 13 & -2.140178 & -0.926651 & -1.267683 & 2.995423 & -1.149872 & 0.000194 \\
\hline 14 & -4.061668 & -0.736328 & 0.251891 & 3.662730 & 1.190823 & -0.000136 \\
\hline 15 & -3.120303 & 0.473325 & 1.299609 & 1.878313 & 1.720115 & -0.000228 \\
\hline
\end{tabular}


TABLE S5: Calculated geometry parameters in principal inertial axes of two stable trans conformers of allyl acetate found in the local minima of the potential energy surface by rotating around the $\mathrm{C}_{8}-\mathrm{C}_{11}$ bond. The atoms are numbered according to the figure given in Tab. S4.

\begin{tabular}{|c|c|c|c|c|c|c|}
\hline \multicolumn{4}{|c|}{ Conformer II } & \multicolumn{3}{|c|}{ Conformer IV } \\
\hline & $\mathrm{X}$ & $\mathrm{Y}$ & $\mathrm{Z}$ & $\mathrm{X}$ & $\mathrm{Y}$ & $\mathrm{Z}$ \\
\hline 1 & 1.443910 & 0.064319 & 0.030854 & -1.360513 & -0.009247 & -0.000058 \\
\hline 2 & 1.659633 & 1.256802 & 0.054154 & -1.792055 & -1.141454 & -0.000120 \\
\hline 3 & 0.202738 & -0.466682 & -0.091075 & -0.037263 & 0.285509 & -0.000037 \\
\hline 4 & 2.476470 & -1.027718 & 0.135031 & -2.180067 & 1.254382 & 0.000093 \\
\hline 5 & 2.278367 & -1.633941 & 1.022134 & -1.938909 & 1.848768 & 0.884404 \\
\hline 6 & 2.412404 & -1.681120 & -0.737852 & -1.936356 & 1.850878 & -0.882077 \\
\hline 7 & 3.468137 & -0.582419 & 0.200475 & -3.238488 & 0.998244 & -0.001641 \\
\hline 8 & -0.857644 & 0.510454 & -0.198172 & 0.828083 & -0.858270 & 0.000136 \\
\hline 9 & -0.887272 & 1.119114 & 0.710284 & 0.615547 & -1.472635 & 0.882107 \\
\hline 10 & -0.640601 & 1.167494 & -1.046399 & 0.615557 & -1.472895 & -0.881655 \\
\hline 11 & -2.132692 & -0.242123 & -0.394481 & 2.253728 & -0.401246 & 0.000074 \\
\hline 12 & -3.177970 & -0.134024 & 0.437873 & 2.663679 & 0.874025 & -0.000116 \\
\hline 13 & -2.189000 & -0.885832 & -1.270055 & 2.985043 & -1.208446 & 0.000196 \\
\hline 14 & -4.102161 & -0.672673 & 0.256978 & 3.722234 & 1.111188 & -0.000150 \\
\hline 15 & -3.131374 & 0.501453 & 1.318175 & 1.954490 & 1.693747 & -0.000237 \\
\hline
\end{tabular}


TABLE S6: Calculated geometry parameters in Gaussian [6] internal coordinate system (called standard orientation) of two stable cis conformers of allyl acetate found in the local minima of the potential energy surface by rotating around the $\mathrm{O}_{3}-\mathrm{C}_{8}$ bond. The atoms are numbered according to the figure given in Tab. S4.

\begin{tabular}{|c|c|c|c|c|c|c|}
\hline \multicolumn{4}{|c|}{ Conformer V/VI (pair of enantiomers) } & \multicolumn{3}{|c|}{ Conformer VII } \\
\hline \multicolumn{2}{|r|}{$\mathrm{X}$} & \multirow{2}{*}{$\frac{Y}{-0.227916}$} & $\mathrm{Z}$ & $\mathrm{X}$ & $\mathrm{Y}$ & $\mathrm{Z}$ \\
\hline 1 & 1.527060 & & -0.060484 & -1.385546 & -0.312377 & -0.015624 \\
\hline 2 & 2.354816 & -1.094510 & -0.206270 & -2.009315 & -1.345183 & -0.050110 \\
\hline 3 & 0.215607 & -0.586999 & 0.053253 & -0.027350 & -0.367487 & -0.126247 \\
\hline 4 & 1.854934 & 1.249937 & -0.025838 & -2.023801 & 1.047922 & 0.169038 \\
\hline 5 & 1.400420 & 1.762024 & -0.878676 & -1.756211 & 1.464121 & 1.144586 \\
\hline 6 & 1.484808 & 1.721256 & 0.887690 & -1.702718 & 1.753187 & -0.600876 \\
\hline 7 & 2.937235 & 1.354919 & -0.078082 & -3.103729 & 0.918727 & 0.121287 \\
\hline 8 & -0.781206 & 0.412770 & 0.335566 & 0.741816 & 0.835132 & -0.161051 \\
\hline 9 & -0.576885 & 0.864432 & 1.313791 & 0.576702 & 1.358191 & -1.112265 \\
\hline 10 & -0.778721 & 1.195075 & -0.430838 & 0.448453 & 1.507433 & 0.653791 \\
\hline 11 & -2.102504 & -0.286856 & 0.352133 & 2.194329 & 0.489876 & -0.016422 \\
\hline 12 & -3.120004 & 0.059749 & -0.448227 & 2.674240 & -0.748072 & 0.158595 \\
\hline 13 & -2.205907 & -1.103865 & 1.062570 & 2.870612 & 1.342369 & -0.062619 \\
\hline 14 & -4.074173 & -0.454082 & -0.401395 & 3.741955 & -0.912597 & 0.256852 \\
\hline 15 & -3.019847 & 0.866208 & -1.169834 & 2.012037 & -1.604956 & 0.202892 \\
\hline \multirow[t]{2}{*}{$\mathrm{a}$} & $\mathrm{A}$ & B & $\mathrm{C}$ & $\mathrm{A}$ & $\mathrm{B}$ & $\mathrm{C}$ \\
\hline & 7.114 & 1.287 & 1.150 & 6.091 & 1.510 & 1.238 \\
\hline \multirow[t]{2}{*}{$\mathrm{b}$} & $\left|\mu_{\mathrm{a}}\right|$ & $\left|\mu_{b}\right|$ & $\left|\mu_{c}\right|$ & $\left|\mu_{\mathrm{a}}\right|$ & $\left|\mu_{b}\right|$ & $\left|\mu_{c}\right|$ \\
\hline & 2.468 & 4.444 & 0.783 & 1.523 & 4.735 & 0.220 \\
\hline $\mathrm{c}$ & \multicolumn{3}{|c|}{-905547.030} & \multicolumn{3}{|c|}{-905545.913} \\
\hline
\end{tabular}


TABLE S7: Calculated geometry parameters in principal inertial axes of two stable cis conformers of allyl acetate found in the local minima of the potential energy surface by rotating around the $\mathrm{O}_{3}-\mathrm{C}_{8}$ bond. The atoms are numbered according to the figure given in Tab. S4.

\begin{tabular}{|c|c|c|c|c|c|c|}
\hline \multicolumn{4}{|c|}{ Conformer V/VI (pair of enantiomers) } & \multicolumn{3}{|c|}{ Conformer VII } \\
\hline & $\mathrm{X}$ & $\mathrm{Y}$ & $\mathrm{Z}$ & $\mathrm{X}$ & $\mathrm{Y}$ & $\mathrm{Z}$ \\
\hline 1 & 1.483618 & -0.126997 & -0.044513 & -1.363679 & -0.203518 & -0.006447 \\
\hline 2 & 2.335845 & -0.974300 & -0.159430 & -2.025949 & -1.212263 & -0.034701 \\
\hline 3 & 0.181895 & -0.518734 & 0.073150 & -0.008698 & -0.310309 & -0.118663 \\
\hline 4 & 1.770381 & 1.359759 & -0.053175 & -1.949968 & 1.180785 & 0.172027 \\
\hline 5 & 1.307167 & 1.832944 & -0.923621 & -1.665355 & 1.591621 & 1.145028 \\
\hline 6 & 1.381783 & 1.848096 & 0.843590 & -1.603773 & 1.869490 & -0.601985 \\
\hline 7 & 2.849675 & 1.493112 & -0.102848 & -3.034069 & 1.092110 & 0.126444 \\
\hline 8 & -0.843835 & 0.461076 & 0.319573 & 0.805151 & 0.862294 & -0.160781 \\
\hline 9 & -0.658071 & 0.947681 & 1.284652 & 0.658347 & 1.386303 & -1.114471 \\
\hline 10 & -0.858218 & 1.219558 & -0.470289 & 0.538598 & 1.549347 & 0.650961 \\
\hline 11 & -2.145408 & -0.274135 & 0.350437 & 2.243860 & 0.463327 & -0.016372 \\
\hline 12 & -3.167141 & 0.019671 & -0.465503 & 2.677092 & -0.790901 & 0.164411 \\
\hline 13 & -2.230601 & -1.071789 & 1.084880 & 2.951689 & 1.289496 & -0.067935 \\
\hline 14 & -4.107043 & -0.518793 & -0.408101 & 3.738009 & -0.995014 & 0.262043 \\
\hline 15 & -3.084833 & 0.806355 & -1.210807 & 1.983165 & -1.621999 & 0.214078 \\
\hline
\end{tabular}

